\title{
The optimal financing mode in a three-stage supply chain under capital constraint of retailers
}

\author{
Yuanyuan Zhang ${ }^{1}$, Lulu Ren ${ }^{2}$ \\ ${ }^{1}$ School of Managemant, Shanghai University, Shanghai, 200444, P.R. China \\ ${ }^{2}$ School of Managemant, Shanghai University, Shanghai, 200444, P.R. China
}

\begin{abstract}
In real life, there is a problem of capital fracture in some enterprises especially small and medium enterprises in the upstream and downstream of the supply chain. In order to research how retailers choose the optimal financing mode, this paper analyzes the double channel and three- stage supply chain under capital constraint of retailers, uses multi-objective nonlinear programming method, constructs the delayed payment financing model and the loan financing model respectively and gives the optimal decentralized decisions of suppliers, manufacturers and retailers under the two modes. The research shows that under the coexistence of the delayed payment financing model and the loan financing model, when the delayed payment rate is equal to the lending rate, if the retailers choose the delayed payment model, then it can not only increase the profits but also improve the market competitiveness and expand the market. This provides certain theory and numerical reference basis for retailers to choose a financing model.
\end{abstract}

\section{Introduction}

Along with the change of the global competition environment and the development of information technology, the development of the industrial economy has shifted from the competition between enterprises to the competition among the supply chains. In the practice of supply chain management, core competitive advantage is not only reflected in the core enterprise or large enterprises but also in the small and medium enterprises. Small and medium enterprises have the small scale, low credit and less financing channels. So financing is very difficult and the cost is relatively high. This may result in capital strand breaking, which affects the development of the entire supply chain, the whole industry and the whole national economy. Therefore, it is of high value to study the financing and operation decisions of the supply chain. Especially it is more practical to study on the financing decisions of the small and medium enterprises.

In recent years, many scholars begin to research on operation and financing decisions of participants in the supply chain under financial constraints. Existing literature research is divided into two pieces. One is the supplier (manufacturer) under capital constraint and the other is the retailer under capital constraint. Among them, the study for operation and financing decisions of suppliers in the supply chain under funding constraints is much more. Tu et al. (2011) study the problem of financing and production decision in the supply chain under capital constraint. The manufacturer can supply the market directly through bank loan financing [1]. Zhao and Li (2012) consider two level supply chain suppliers face financial constraints and research financing and pricing decisions in the noncompetitive market when suppliers have different initial funding [2].

In the existing literature, supply chain financing decisions for retailers under the capital constraint is relatively few. Chen et al (2016) study supply chain financing and operation decisions, which is composed of a single supplier and a single capital constrained retailer. When retailers are under the capital constraint, they get the loan from the capital market to obtain the financing service. [3] Yan and Sun (2013) study the Stackelberg game model of retailers under the capital constraint [4]. In order to make the model more realistic, Li and Chen (2015) study a multi-channel supply chain model consisting of a manufacturer and multiple retailers and analyze the optimal decisions in borrow financing and deferred financing mode for the manufacturers and retailers under the capital constraint of the retailer [5].

In summary, from previous literature research, about financing and operational decision making in the supply chain under the financial constraints of retailers, it is found that literatures are based mostly on a two-stage supply chain consisting of a single supplier and a single retailer or a single manufacturer and a single retailer and rarely based on a three-level supply chain, ignoring the multilevel and complexity of supply chain in real management practice. Therefore, it is worth exploring the practicality of theoretical and model results in the multistage supply chain. In this paper, combining the management practice in real life, based on the research of scholars at home and abroad, the research on financing decision of capital constraint is extended to the three-stage supply chain. The structure is organized as follows: Considering the three-stage supply chain consisting of 
single supplier, single manufacturer and single retailer and dual channels sale as the research object, section 2 uses the Stackelberg game theory to model and analyze, and explores the operation mode of the three-stage supply chain, the optimal decision-making problem of supply chain members and the impact of the supply chain members' benefits under the operation mode of the loan financing and deferred payment. Section 3 performs case study and simulates the model quantitatively through the EXCEL data analysis software. Finally, Section 4 concludes the paper, providing a theoretical and numerical basis for the actual decision and points out further work.

\section{Fundamental model}

\subsection{Variable definition and relevant assumptions}

Assuming in a three-stage supply chain consisting of a single supplier, a single manufacturer and a single retailer, manufacturers process products providing by suppliers. The entire supply chain exists two sales channels of manufacturers direct sales and retail outlets. It only manufactures and sales one product and there is no shortage phenomenon. Assuming that the retailer's own initial capital is $\mathrm{B}$, there is no shortage of funds for suppliers and manufacturers. At the beginning of the sales cycle, retailers can apply for deferred payment from the manufacturer or apply for loans from the bank if there are insufficient funds, regardless of the repurchase. Specific variables are defined and described as follows:

- $p_{m}$ : Manufacturer direct selling price;

- $p_{r}:$ Retail unit price;

- $d_{m}$ : Consumers demand for manufacturer selling directly to;

- $d_{r}$ : Consumer demand for retailer sales;

- $w_{s}$ : Wholesale prices of suppliers to manufacturers;

- $w_{m}$ : Wholesale price of manufacturer to retailer;

- c: Unit cost of production;

- $c_{m}$ : Total production cost per unit of manufacturer;

- B : Initial free funds for retailers;

- $\delta$ : Interest rates for manufacturers postponing payment;

- $r_{b}:$ Bank lending rate;

- $\pi_{s}$ : Supplier's sales profit;

- $\pi_{m}$ : Manufacturer's sales profit;

- $\pi_{r}$ : Retailer's sales profit.

For the sake of simplicity, make the following assumptions:

Hypothesis 1: $d_{m}=(1-t) a-b_{1} p_{m}+b_{2} p_{r}, \quad d_{r}=$ ta $-b_{1} p_{r}+b_{2} p_{m}$, where $a$ is the total potential consumer demand in the market, $t$ is the proportion of retail market in the total market, $b_{1}$ is price elasticity of demand on two sales channels of supply. $b_{2}$ is the degree of consumer transfer due to the different prices of the two channels, $b_{1}>b_{2}$;

Hypothesis 2: $c_{m}=w_{s}+m$, where $m$ is the unit processing cost of manufacturers making the raw material into the finished product;
Hypothesis 3: Suppliers, manufacturers, retailers and banks all have information that is symmetrical, and the risk-free interest rate of the company's funds is zero.

\subsection{Decentralized decision model of supply chain with sufficient funds for retailers}

$w_{s}{ }^{0},{w_{m}}^{0}, p_{m}{ }^{0}, p_{r}{ }^{0}$ represent the optimal decisions of the supplier, manufacturer and retailer respectively when the retailer's initial free capital is adequate. The profit function of the three is expressed as $\pi_{s}^{0}, \pi_{m}^{0}, \pi_{r}^{0}$ and the specific functions are as follows:

$$
\begin{aligned}
& \pi_{s}^{0}=\left(w_{s}-c\right)\left(d_{m}+d_{r}\right), \\
& \pi_{m}^{0}=\left(p_{m}-c_{m}\right) d_{m}+\left(w_{m}-c_{m}\right) d_{r}, \\
& \pi_{r}^{0}=\left(p_{r}-w_{m}\right) d_{r} .
\end{aligned}
$$

In decentralized decision-making, suppliers first determine the supplier wholesale price $w_{s}$. The manufacturer's wholesale price $w_{m}$ and the manufacturer's direct selling price $p_{m}$ are jointly determined by the manufacturer according to the supplier's wholesale price decision and direct selling demand function. Finally, the retail price $p_{r}$ is determined by the retailer based on the manufacturer's decision and demand function, in order to achieve the optimal profit in the initial capital adequacy. The optimal decentralized decision in the case of capital adequacy is introduced by using the Stackelberg game theory and reverse order decision research.

Retailers determine the optimal retail price based on the manufacturer's direct selling price of $p_{m}$ and the manufacturer's wholesale price $w_{m}$ (and also determines its order quantity according to the demand function). Plugging $d_{r}=t a-b_{1} p_{r}+b_{2} p_{m}$ into the retailer's profit function type (3), we can obtain the following new retailer's profit function:

$$
\begin{gathered}
\pi_{r}^{0}\left(p_{r}\right)=-b_{1} p_{r}{ }^{2}+\left(t a+b_{2} p_{m}+b_{1} w_{m}\right) p_{r} \\
-\left(t a+b_{2} p_{m}\right) w_{m} .
\end{gathered}
$$

Take derivative of the target function $\pi_{r}^{0}\left(p_{r}\right)$ for $p_{r}$ of first-order derivative and second-order derivative. It is easy to prove that $\pi_{r}^{0}$ is a concave function for $p_{r}$. The process is as follows:

$$
\begin{gathered}
\pi_{r}^{0,}=-2 b_{1} p_{r}+t a+b_{2} p_{m}+b_{1} w_{m}, \\
\pi_{r}^{0 \prime}=-2 b_{1}<0 .
\end{gathered}
$$

Because the two order derivative of the objective function $\pi_{r}^{0 "}$ is less than zero. That is a concave function $\pi_{r}^{0}$ and it has a maximum value. Make $\pi_{r}^{0}=0$, optimal value of $p_{r}$ can be obtained with $p_{r}{ }^{0}$ indicating the following:

$$
p_{r}{ }^{0}=\frac{t a+b_{2} p_{m}+w_{m} b_{1}}{2 b_{1}} .
$$

$d_{m}=(1-t) a-b_{1} p_{m}+b_{2} p_{r}, d_{r}=t a-b_{1} p_{r}+$ $b_{2} p_{m}$ substitute profit function of manufacturers (2). At the same time, put algebraic expression $p_{r}{ }^{0}$ about $w_{m}$, $p_{m}$ into manufacturer's profit function (2), and new profit function of manufacturers is obtained as follows: 


$$
\begin{aligned}
& \pi_{m}^{0}\left(w_{m}, p_{m}\right) \\
& =\left(p_{m}-c_{m}\right)\left[(1-t) a-b_{1} p_{m}\right. \\
& \left.+b_{2} \frac{t a+b_{2} p_{m}+w_{m} b_{1}}{2 b_{1}}\right] \\
& +\left(w_{m}-c_{m}\right)\left[t a-\frac{t a+b_{2} p_{m}+w_{m} b_{1}}{2}\right. \\
& \left.+b_{2} p_{m}\right] .
\end{aligned}
$$

Take derivative of the target function $\pi_{m}^{0}\left(w_{m}, p_{m}\right)$ for manufacturers wholesale prices $w_{m}$ and manufacturers direct price $p_{m}$ of first-order derivative and second-order derivative. Then the results can be obtained as follows:

$$
\begin{aligned}
& \frac{\partial_{\pi_{m}^{0}}}{\partial_{p_{m}}}=(1-t) a-b_{1} p_{m}+\frac{b_{2}}{2 b_{1}}\left(t a+b_{2} p_{m}+b_{1} w_{m}\right) \\
& +\left(\frac{b_{2}{ }^{2}}{2 b_{1}}-b_{1}\right)\left(p_{m}-c_{m}\right) \\
& +\frac{b_{2}}{2}\left(w_{m}-c_{m}\right) \text {, } \\
& \frac{\partial_{\pi_{m}^{0}}}{\partial_{w_{m}}}=\frac{b_{2}}{2}\left(p_{m}-c_{m}\right)+t a-\frac{1}{2}\left(t a+b_{2} p_{m}+b_{1} w_{m}\right) \\
& +b_{2} p_{m}-\frac{1}{2} b_{1}\left(w_{m}-c_{m}\right), \\
& \frac{\partial^{2} \pi_{m}^{0}}{\partial_{p_{m}{ }^{2}}}=\frac{b_{2}{ }^{2}-2 b_{1}{ }^{2}}{b_{1}} \\
& \frac{\partial^{2} \pi_{m}^{0}}{\partial_{p_{m}} \partial_{w_{m}}}=b_{2} \\
& \frac{\partial^{2} \pi_{m}^{0}}{\partial_{w_{m}^{2}}}=-b_{1} \\
& \frac{\partial^{2} \pi_{m}^{0}}{\partial_{w_{m}} \partial_{p_{m}}}=b_{2}
\end{aligned}
$$

From the results above, it is can be proved that $\pi_{m}^{0}$ is the joint concave function about $w_{m}, p_{m}$ and the function $\pi_{m}^{0}$ can get the optimal solution. Make $\frac{\partial_{\pi_{m}^{0}}}{\partial_{p_{m}}}=0$ and $\frac{\partial_{\pi_{m}^{0}}}{\partial_{w_{m}}}=0$ get solution together and put the solution into the algebraic expression $p_{r}{ }^{0}$. The optimal decisions of manufacturers and retailers $w_{m}{ }^{0}, p_{m}{ }^{0}, p_{r}{ }^{0}$ denoted by $c_{m}$ can be obtained. They are as follows:

$$
\begin{gathered}
w_{m}{ }^{0}=\frac{1}{2\left(b_{1}{ }^{2}-b_{2}{ }^{2}\right)}\left[(1-t) a b_{2}+t a b_{1}\right. \\
\left.+\left(b_{1}{ }^{2}-b_{2}{ }^{2}\right) c_{m}\right]
\end{gathered}
$$

From $c_{m}=w_{s}+m$, optimal decision of manufacturers and retailers $w_{m}{ }^{0}, p_{m}{ }^{0}, p_{r}{ }^{0}$ can be obtained as the algebraic expression $w_{s} \cdot d_{m}=(1-$ $t) a-b_{1} p_{m}+b_{2} p_{r}, \quad d_{r}=t a-b_{1} p_{r}+b_{2} p_{m} \quad$ are substituted into the supplier's profit function type (1). At the same time, $p_{m}{ }^{0}, p_{r}{ }^{0}$ about $w_{s}$ are substituted into profit function of suppliers (1). Then new profit function of suppliers $\pi_{s}^{0}\left(w_{s}\right)$ is obtained. Take derivative of it for the wholesale price of suppliers $w_{s}$, and similarly we can get the optimal wholesale price of the suppliers $w_{S}{ }^{0}$. Then put $w_{s}{ }^{0}$ into $w_{m}{ }^{0}, p_{m}{ }^{0}, p_{r}{ }^{0}$ and we can get the following conclusions:

Proposition 1. In decentralized decision making, for the dual channel supply chain of suppliers, manufacturers and retailers in initial capital adequacy, the optimal decision-making suppliers, manufacturers and retailers $w_{s}{ }^{0}, w_{m}{ }^{0}, p_{m}{ }^{0}, p_{r}{ }^{0}$ are expressed as follows respectively:

$$
\begin{aligned}
& w_{s}{ }^{0}= \frac{1}{2\left(3 b_{1}+b_{2}\right)\left(b_{1}-b_{2}\right)}\left[2 a b_{1}-t a\left(b_{1}-b_{2}\right)\right] \\
&+\frac{1}{2}(c-m), \\
& p_{m}{ }^{0}= \frac{1}{2\left(b_{1}{ }^{2}-b_{2}{ }^{2}\right)}\left[a b_{1}(1-t)+t a b_{2}\right]+\frac{1}{4}(c+m) \\
&+ \frac{1}{4\left(3 b_{1}+b_{2}\right)\left(b_{1}-b_{2}\right)}\left[2 a b_{1}-t a\left(b_{1}-b_{2}\right)\right], \\
& w_{m}{ }^{0}= \frac{1}{2\left(b_{1}{ }^{2}-b_{2}{ }^{2}\right)}\left[a b_{2}(1-t)+t a b_{1}\right]+\frac{1}{4}(c+m) \\
&+\frac{1}{4\left(3 b_{1}+b_{2}\right)\left(b_{1}-b_{2}\right)}\left[2 a b_{1}-t a\left(b_{1}-b_{2}\right)\right], \\
& \begin{aligned}
p_{r}{ }^{0}=\frac{1}{4 b_{1}\left(b_{1}{ }^{2}-b_{2}{ }^{2}\right)}\left[2 a b_{1} b_{2}(1-t)\right. \\
\left.+t a\left(3 b_{1}{ }^{2}-b_{2}{ }^{2}\right)\right]
\end{aligned} \\
&+ \frac{b_{1}+b_{2}}{8 b_{1}}(c+m)+\frac{b_{1}+b_{2}}{8 b_{1}\left(3 b_{1}+b_{2}\right)\left(b_{1}-b_{2}\right)} \\
& {\left[2 a b_{1}-t a\left(b_{1}-b_{2}\right)\right] . }
\end{aligned}
$$

\subsection{Decentralized decision model of supply chain under the mode of retailer delayed payment}

The postponement payment mode refers to in order period, retailers of insufficient funds firstly pay to manufacturers with the existing initial free money, and after they sell the products and receive cash, then pay to manufacturer of the remaining balance of payment at a certain interest rate. On the assumption that the risk-free interest rate is zero, namely, capital operation of supply chain participants does not consider the time cost. Further studies can consider the issue of funds discount. The discount of the balance of order, retailer and manufacturer's sales and the impact of risk-free interest rate on financing decision making can be discussed.

Capital deficiency of the retailers refers to on ordering stage the initial funding amount $\mathrm{B} \leq \mathrm{w}_{\mathrm{m}}{ }^{0} \mathrm{~d}_{\mathrm{r}}$, and then retailers choose to defer payment in order to obtain more revenue. Delayed payment of retailers refers to in the ordering phase, retailers of insufficient funds first pay a partial order payment with initial capital of free. Goods of $\frac{B}{w_{m}}$ units are obtained at the wholesale price $w_{m}$ and the payment $w_{m} d_{r}-B$ is required for the remaining $\mathrm{d}_{\mathrm{r}}-\frac{\mathrm{B}}{\mathrm{w}_{\mathrm{m}}}$ unit commodity. The manufacturers allow retailers to defer payment at per unit price $(1+\delta) \mathrm{w}_{\mathrm{m}}$, 
$(\delta \geq 0)$ after the implementation of the requirements. Delayed payment financing model can be regarded as a model of trade credit financing.

When the retailer's initial free funds are in short supply and $w_{s}{ }^{1}, w_{m}{ }^{1}, p_{m}{ }^{1}, p_{r}{ }^{1}$ is denoted optimal decision of the suppliers, manufacturers and retailers in delayed payment financing mode respectively. The profit function is $\pi_{s}{ }^{1}, \pi_{m}{ }^{1}, \pi_{r}{ }^{1}$ respectively, and they are expressed as follows:

$$
\begin{gathered}
\pi_{s}{ }^{1}=\left(w_{s}-c\right)\left(d_{m}+d_{r}\right) \\
\pi_{m}{ }^{1}=\left(p_{m}-c_{m}\right) d_{m}+\left(w_{m}-c_{m}\right) \frac{B}{w_{m}} \\
+\left[(1+\delta) w_{m}-c_{m}\right]\left(d_{r}-\frac{B}{w_{m}}\right) \\
\pi_{r}{ }^{1}=\frac{B}{w_{m}}\left(p_{r}-w_{m}\right) \\
\quad+\left[p_{r}-(1+\delta) w_{m}\right]\left(d_{r}-\frac{B}{w_{m}}\right) .
\end{gathered}
$$

When the initial free funds of retailers are in short supply, in the decentralized decision-making, the analysis process of the sequence of decisions for suppliers, manufacturers, retailers is similar to the situation when the capital is abundant above. The optimal decentralized decision making of the suppliers, manufacturers and the retailers is obtained with the research method of reverse order decision making when the retailers are of capital shortage. $d_{r}=t a-b_{1} p_{r}+b_{2} p_{m}$ is substituted into the retailer's profit function (6), then we can obtain the following new profit function of retailers:

$$
\begin{gathered}
\pi_{r}^{1}\left(p_{r}\right)=\frac{B}{w_{m}}\left(p_{r}-w_{m}\right)+\left[p_{r}-(1+\delta) w_{m}\right] \\
\left(t a-b_{1} p_{r}+b_{2} p_{m}-\frac{B}{w_{m}}\right) .
\end{gathered}
$$

Take derivative of the target function $\pi_{r}^{1}\left(p_{r}\right)$ for $p_{r}$ of first-order derivative and second-order derivative and the results are as follows:

$$
\begin{gathered}
\pi_{r}{ }^{{ }^{\prime}}=(1+\delta) b_{1} w_{m}+b_{2} p_{m}+t a-2 b_{1} p_{r}, \\
\pi_{r}{ }^{1 "}=-2 b_{1} .
\end{gathered}
$$

Due to $\pi_{r}{ }^{1 "}<0$, it can be proved that $\pi_{r}{ }^{1}$ is a concave function of $p_{r}$. So make $\pi_{r}{ }^{1}=0$, the best decision $p_{r}{ }^{1}$ can be got as follows:

$$
\begin{gathered}
p_{r}{ }^{1}=\frac{(1+\delta) b_{1} w_{m}+t a+b_{2} p_{m}}{2 b_{1}} . \\
d_{m}=(1-t) a-b_{1} p_{m}+b_{2} p_{r}, d_{r}=t a-b_{1} p_{r}+
\end{gathered}
$$
$b_{2} p_{m}$ are substituted into manufacturer's profit function (5), and at the same time algebraic $p_{r}{ }^{1}$ about $w_{m}, p_{m}$ is substituted into manufacturer's profit function (5). Then the new manufacturers profit function can be obtained as follows:

$$
\begin{aligned}
\pi_{m}{ }^{1}\left(w_{m}, p_{m}\right)= & \left(p_{m}-c_{m}\right)\left[(1-t) a-b_{1} p_{m}\right. \\
& \left.+b_{2} p_{r}\right] \\
+ & \left(1+\delta-c_{m}\right)\left(a-b_{1} p_{r}+b_{2} p_{m}\right) \\
& -\delta B .
\end{aligned}
$$

Take derivative of the target function $\pi_{m}{ }^{1}\left(w_{m}, p_{m}\right)$ for manufacturers wholesale prices $w_{m}$ and manufacturers direct price $p_{m}$ for the first-order derivative and second-order derivative respectively and the results are as follows:

$$
\begin{gathered}
\frac{\partial_{\pi_{m}{ }^{1}}}{\partial_{p_{m}}}=(1-t) a+\left(\frac{b_{2}{ }^{2}}{b_{1}}-2 b_{1}\right) p_{m}+(1+\delta) b_{2} w_{m} \\
+\frac{2 b_{1}{ }^{2}-b_{2}{ }^{2}-b_{1} b_{2}}{2 b_{1}} c_{m}+\frac{t a b_{2}}{2 b_{1}} \\
\frac{\partial_{\pi_{m}}{ }^{1}}{\partial_{w_{m}}}=(1+\delta) b_{2} p_{m}-(1+\delta)^{2} b_{1} w_{m} \\
+\frac{1}{2}(1+\delta)\left(t a+b_{1} c_{m}-b_{2} c_{m}\right) \\
\frac{\partial^{2} \pi_{m}{ }^{1}}{\partial_{p_{m}{ }^{2}}}=\frac{b_{2}{ }^{2}}{b_{1}}-2 b_{1} ; \quad \frac{\partial^{2} \pi_{m}{ }^{1}}{\partial_{w_{m}{ }^{2}}}=-(1+\delta)^{2} b_{1} \\
\frac{\partial_{\pi_{m}{ }^{2}}^{2}}{\partial_{p_{m}} \partial_{w_{m}}}=(1+\delta) b_{2} ; \quad \frac{\partial^{2} \pi_{m}{ }^{1}}{\partial_{w_{m}} \partial_{p_{m}}}=(1+\delta) b_{2}
\end{gathered}
$$

From the above results, we can prove that $\pi_{m}{ }^{1}$ is a joint concave function about $w_{m}, p_{m}$ and the function $\pi_{m}{ }^{1}$ can get the optimal solution. Make $\partial_{\pi_{m}{ }^{1}} / \partial_{p_{m}}=0$ and $\partial_{\pi_{m}} 1 / \partial_{w_{m}}=0$ joint solving, and put the solution $w_{m}{ }^{1}, p_{m}{ }^{1}$ into algebraic $p_{r}{ }^{1}$. The optimal decision of manufacturers and retailers $w_{m}{ }^{1}, p_{m}{ }^{1}, p_{r}{ }^{1}$ represented by $c_{m}$ can be obtained as follows:

$$
\begin{gathered}
w_{m}{ }^{1}=\frac{1}{2(1+\delta)\left(b_{1}{ }^{2}-b_{2}{ }^{2}\right)} \\
{\left[(1-t) a b_{2}+t a b_{1}+\left(b_{1}{ }^{2}-b_{2}{ }^{2}\right) c_{m}\right]} \\
p_{m}{ }^{1}=\frac{1}{2\left(b_{1}{ }^{2}-b_{2}{ }^{2}\right)}\left[(1-t) a b_{1}+t a b_{2}\right. \\
\left.+\left(b_{1}{ }^{2}-b_{2}{ }^{2}\right) c_{m}\right] \\
p_{r}{ }^{1}=\frac{1}{4 b_{1}\left(b_{1}{ }^{2}-b_{2}{ }^{2}\right)}\left[2(1-t) a b_{1} b_{2}\right. \\
+{ }^{2}\left(3 b_{1}{ }^{2}-b_{2}{ }^{2}\right) t a \\
\left.+\left(b_{1}{ }^{3}-b_{1} b_{2}{ }^{2}+b_{1}{ }^{2} b_{2}-b_{2}{ }^{3}\right) c_{m}\right] .
\end{gathered}
$$

Because $c_{m}=w_{s}+m$, the optimal strategies of the manufacturers and the retailers $w_{m}{ }^{1}, p_{m}{ }^{1}, p_{r}{ }^{1}$ about $w_{s}$ can be obtained. $d_{m}=(1-t) a-b_{1} p_{m}+b_{2} p_{r}$, $d_{r}=t a-b_{1} p_{r}+b_{2} p_{m}$ are substituted into supplier profit function (4), and $p_{m}{ }^{1}, p_{r}{ }^{1}$ about $w_{s}$ are substituted into supplier profit function (4). Then a new supplier's profit function $\pi_{s}{ }^{1}\left(w_{s}\right)$ can be obtained. Take derivative of the supplier's wholesale price $w_{s}$, and the wholesale price of the supplier optimal decision $w_{s}{ }^{1}$, can be obtained. Then $w_{s}{ }^{1}$ are substituted into $w_{m}{ }^{1}, p_{m}{ }^{1}$, $p_{r}{ }^{1}$ and the following conclusions can be got.

Proposition 2. In decentralized decision making, for the two channel supply chain of the retailer's initial free funds shortage, when the interest rate $\delta$ is taken to postpone the payment method, the optimal decision of the suppliers, the manufacturers and the retailers $w_{s}{ }^{1}, w_{m}{ }^{1}, p_{m}{ }^{1}, p_{r}{ }^{1}$ is obtained respectively: 


$$
\begin{gathered}
w_{s}{ }^{1}=\frac{1}{2\left(3 b_{1}+b_{2}\right)\left(b_{1}-b_{2}\right)} \\
\left.p_{m}{ }^{1}=\frac{1}{2\left(b_{1}{ }^{2}-b_{2}{ }^{2}\right)}\left[a b_{1}-t a\left(b_{1}-b_{2}\right)\right]+\frac{1}{2}(1-t)+t a b_{2}\right]+\frac{1}{4}(c+m) \\
+\frac{1}{4\left(3 b_{1}+b_{2}\right)\left(b_{1}-b_{2}\right)}\left[2 a b_{1}-t a\left(b_{1}-b_{2}\right)\right], \\
w_{m}{ }^{1}=\frac{1}{2\left(b_{1}{ }^{2}-b_{2}{ }^{2}\right)(1+\delta)} \\
{\left[a b_{2}(1-t)+t a b_{1}\right]+\frac{1}{4(1+\delta)}(c+m)} \\
+\frac{1}{4\left(3 b_{1}+b_{2}\right)\left(b_{1}-b_{2}\right)(1+\delta)} \\
p_{r}{ }^{1}=\frac{\left[2 a b_{1}-t a\left(b_{1}-b_{2}\right)\right]}{4 b_{1}\left(b_{1}{ }^{2}-b_{2}{ }^{2}\right)}\left[2 a b_{1} b_{2}(1-t)\right. \\
\left.+t a\left(3 b_{1}{ }^{2}-b_{2}{ }^{2}\right)\right]+\frac{b_{1}+b_{2}}{8 b_{1}}(c+m) \\
+\frac{b_{1}+b_{2}}{8 b_{1}\left(3 b_{1}+b_{2}\right)\left(b_{1}-b_{2}\right)} \\
{\left[2 a b_{1}-t a\left(b_{1}-b_{2}\right)\right]}
\end{gathered}
$$

From the comparison of $w_{s}{ }^{1}, w_{m}{ }^{1}, p_{m}{ }^{1}, p_{r}{ }^{1}$ and $w_{s}{ }^{0}, w_{m}{ }^{0}, p_{m}{ }^{0}, p_{r}{ }^{0}$, it can be found that dual channel supply chain decentralized decisions of retailers capital constraints on defer payment financing mode, manufacturers provide lower the manufacturer's wholesale price $\left(w_{m}{ }^{0}=(1+\delta) w_{m}{ }^{1}, \quad \delta>0\right)$ to attract retailers to increase the order quantity. It can be seen by proposition manufacturers will determine the wholesale price basing on the deferred interest rate $\delta$, and it's $1 /(1+\delta)$ times the wholesale price when the retailer is well-funded .That is the higher the interest rate, manufacturer's wholesale price will be lower.

At the same time, the manufacturers wholesale prices, the optimal retail price, manufacturers selling price and supplier's wholesale prices will not be affected by the influence of retailer capital constraints, and the optimal decisions are the same with the retailer capital adequacy $\left(w_{s}{ }^{1}=w_{s}{ }^{0}, \quad p_{m}{ }^{1}=p_{m}{ }^{0}, \quad p_{r}{ }^{1}=p_{r}{ }^{0}\right)$. The consumption demand function shows that the total demand of the dual channel supply chain will not change because of lack of funds for retailers. Due to the constant demand of manufacturers and retailers $\left(p_{m}{ }^{1}=p_{m}{ }^{0}, p_{r}{ }^{1}=p_{r}{ }^{0}\right)$, so the product demand of manufacturer to supplier's will be unchanged, and supplier's wholesale price will also be unchanged $\left(w_{s}{ }^{1}=w_{s}{ }^{0}\right)$. Therefore the ultimate benefit for suppliers will not be affected.

\subsection{Decentralized decision model of supply chain under the mode of retailer credit payment}

Retailers loan payment model refers to that underfunded retailers are required to loan $\mathrm{D}$ from the bank at interest rate $r_{b}$ before ordering in order to pay the ordering cost $w_{m} d_{r}-B$ and return principal and interest $D\left(1+r_{b}\right)$ after sales. In this mode, the suppliers, manufacturers and retailers make decisions respectively. Because the funds risk-free interest rate is generally lower than the bank loan interest rate (in this paper, it is assumed that the risk-free interest rate is 0 ) and there is a hypothesis that the demand function is predictable (demand is a function of potential market demand and sales price), information is symmetric and bank loan don't need to consider the risks of uncertain demand.

When the retailer's initial free funds is short, on this financing mode, $w_{s}{ }^{*}, w_{m}{ }^{*}, p_{m}{ }^{*}, p_{r}{ }^{*}$ indicates the optimal decision of suppliers, manufacturers and retailers respectively. The profit function is $\pi_{s}{ }^{*}, \pi_{m}{ }^{*}, \pi_{r}{ }^{*}$ respectively, and specific functions are as follows:

$$
\begin{aligned}
& \pi_{s}{ }^{*}=\left(w_{s}-c\right)\left(d_{m}+d_{r}\right), \\
& \pi_{m}{ }^{*}=\left(p_{m}-c_{m}\right) d_{m}+\left(w_{m}-c_{m}\right) d_{r}, \\
& \pi_{r}{ }^{*}=\left(p_{r}-w_{m}\right) d_{r}-\left(w_{m} d_{r}-B\right) r_{b} .
\end{aligned}
$$

When the initial free funds of retailers is in short supply, in the decentralized decision-making, the analysis process of the sequence of decisions for suppliers, manufacturers, retailers is similar to the situation when the capital is abundant above. The optimal decentralized decision making of the suppliers, manufacturers and the retailers is obtained with the research method of reverse order decision making when the retailers are of capital shortage. $d_{r}=t a-b_{1} p_{r}+b_{2} p_{m}$ is substituted into the retailer's profit function (9), then we can obtain the following new profit function of retailers:

$$
\begin{aligned}
& \pi_{r}{ }^{*}\left(p_{r}\right)=\left(p_{r}-w_{m}\right)\left(t a-b_{1} p_{r}+b_{2} p_{m}\right)- \\
& {\left[w_{m}\left(t a-b_{1} p_{r}+b_{2} p_{m}\right)-B\right] r_{b} .}
\end{aligned}
$$

Take derivative of the target function $\pi_{r}{ }^{*}\left(p_{r}\right)$ for $p_{r}$ of first-order derivative and second-order derivative and the results are as follows:

$$
\begin{gathered}
\pi_{r}{ }^{*,}=\left(1+r_{b}\right) b_{1} w_{m}+b_{2} p_{m}+t a-2 b_{1} p_{r}, \\
\pi_{r}{ }^{*,}=-2 b_{1} .
\end{gathered}
$$

Due to $\pi_{r}{ }^{* \prime}<0$, it can be proved that $\pi_{r}{ }^{*}$ is a concave function of $p_{r}$. So make $\pi_{r}{ }^{*}=0$, the best decision $p_{r}{ }^{*}$ can be got as follows:

$$
p_{r}{ }^{*}=\frac{\left(1+r_{b}\right) b_{1} w_{m}+t a+b_{2} p_{m}}{2 b_{1}} .
$$

$d_{m}=(1-t) a-b_{1} p_{m}+b_{2} p_{r} \quad, \quad d_{r}=t a-b_{1} p_{r}+$ $b_{2} p_{m}$ are substituted into manufacturer's profit function (8), and at the same time algebraic $p_{r}{ }^{*}$ about $w_{m}, p_{m}$ is substituted into manufacturer's profit function (8). Then the new manufacturers profit function can be obtained as follows:

$$
\begin{gathered}
\pi_{m}{ }^{*}\left(w_{m}, p_{m}\right)=\left(p_{m}-c_{m}\right) \\
{\left[(1-t) a-b_{1} p_{m}+b_{2} \frac{\left(1+r_{b}\right) b_{1} w_{m}+t a+b_{2} p_{m}}{2 b_{1}}\right]} \\
+\left(w_{m}-c_{m}\right) \\
{\left[t a-\frac{\left(1+r_{b}\right) b_{1} w_{m}+t a+b_{2} p_{m}}{2}+b_{2} p_{m}\right] .}
\end{gathered}
$$


Take derivative of the target function $\pi_{m}{ }^{*}\left(w_{m}, p_{m}\right)$ for manufacturers wholesale prices $w_{m}$ and manufacturers direct price $p_{m}$ for the first-order derivative and second-order derivative respectively and the results are as follows:

$$
\begin{gathered}
\frac{\partial_{\pi_{m}{ }^{*}}}{\partial_{p_{m}}}=(1-t) a+\left(\frac{b_{2}{ }^{2}}{b_{1}}-2 b_{1}\right) p_{m}+\frac{\left(2+r_{b}\right)}{2} b_{2} w_{m} \\
+\frac{2 b_{1}{ }^{2}-b_{2}{ }^{2}-b_{1} b_{2}}{2 b_{1}} c_{m}+\frac{t a b_{2}}{2 b_{1}} \\
\frac{\partial_{\pi_{m}}{ }^{*}}{\partial_{w_{m}}}=\frac{\left(2+r_{b}\right)}{2} b_{2} p_{m}-\left(1+r_{b}\right) b_{1} w_{m} \\
+\frac{\left(1+r_{b}\right)}{2}\left(b_{1}-b_{2}\right) c_{m}+\frac{t a}{2} \\
\frac{\partial_{\pi_{m}}^{2}}{\partial_{p_{m}{ }^{2}}}=\frac{b_{2}{ }^{2}}{b_{1}}-2 b_{1} ; \quad \frac{\partial^{2} \pi_{m}{ }^{*}}{\partial_{w_{m}{ }^{2}}}=-\left(1+r_{b}\right) b_{1} \\
\frac{\partial_{\pi_{m}}^{2}}{\partial_{p_{m}} \partial_{w_{m}}}=\frac{\left(2+r_{b}\right)}{2} b_{2} ; \quad \frac{\partial^{2}{ }_{\pi_{m}}{ }^{*}}{\partial_{w_{m}} \partial_{p_{m}}}=\frac{\left(2+r_{b}\right)}{2} b_{2} .
\end{gathered}
$$

From the above results, we can prove that $\pi_{m}{ }^{*}$ is a joint concave function about $w_{m}, p_{m}$ and the function $\pi_{m}{ }^{*}$ can get the optimal solution. Make $\partial_{\pi_{m}{ }^{*}} / \partial_{p_{m}}=0$ and $\partial_{\pi_{m}}{ }^{*} / \partial_{w_{m}}=0$ joint solving, and put the solution $w_{m}{ }^{*}, p_{m}{ }^{*}$ into algebraic $p_{r}{ }^{*}$. The optimal decision of manufacturers and retailers $w_{m}{ }^{*}, p_{m}{ }^{*}, p_{r}{ }^{*}$ represented by $c_{m}$ can be obtained as follows:

$$
\begin{aligned}
& w_{m}{ }^{*}=\frac{1}{b_{1} M}\left[2 b_{1} b_{2}\left(2+r_{b}\right)(1-t) a\right. \\
& +\left(4 b_{1}{ }^{2}+b_{2}{ }^{2} r_{b}\right) t a \\
& +\left(b_{1}-b_{2}\right)\left(4 b_{1}{ }^{2}+4 b_{1} b_{2}-b_{2}{ }^{2} r_{b}\right. \\
& \left.\left.+2 b_{1} b_{2} r_{b}+4 b_{1}{ }^{2} r_{b}\right) c_{m}\right] \text {, } \\
& p_{m}{ }^{*}=\frac{1}{M}\left[4(1-t)\left(1+r_{b}\right) a b_{1}+\left(4+3 r_{b}\right) t a b_{2}\right. \\
& +\left(b_{1}-b_{2}\right)\left(4 b_{1}+4 b_{2}+r_{b} b_{2}\right)(1 \\
& \left.\left.+r_{b}\right) c_{m}\right] \text {, } \\
& p_{r}^{*}=\frac{\left(1+r_{b}\right)}{b_{1} M}\left[b_{1} b_{2}\left(4+r_{b}\right)(1-t) a\right. \\
& +2\left(3{b_{1}}^{2}-{b_{2}}^{2}\right) t a+\left(b_{1}-b_{2}\right) \\
& \left.\left[2\left(b_{1}+b_{2}\right)^{2}+b_{1} r_{b}\left(2 b_{1}+b_{2}\right)\right] c_{m}\right] \text {, } \\
& \text { where } \mathrm{M}=8\left({b_{1}}^{2}-{b_{2}}^{2}\right)\left(1+r_{b}\right)-{r_{b}}^{2}{b_{2}}^{2} \text {. }
\end{aligned}
$$

Because $c_{m}=w_{s}+m$, the optimal strategies of the manufacturers and the retailers $w_{m}{ }^{*}, p_{m}{ }^{*}, p_{r}{ }^{*}$ about $w_{s}$ can be obtained. $d_{m}=(1-t) a-b_{1} p_{m}+b_{2} p_{r}$, $d_{r}=t a-b_{1} p_{r}+b_{2} p_{m}$ are substituted into supplier profit function (7), and $p_{m}{ }^{*}, p_{r}{ }^{*}$ about $w_{s}$ are substituted into supplier profit function (7). Then a new supplier's profit function $\pi_{s}{ }^{*}\left(w_{s}\right)$ can be obtained. Take derivative of the wholesale price of suppliers $w_{s}$ of firstorder and second-order derivative. The results are as follows:

$$
\begin{gathered}
\pi_{s}^{*}\left(w_{s}\right)^{\prime}=\frac{1}{M}\left(b_{2}-b_{1}\right)(1-t)\left(1+r_{b}\right) a\left[4\left(b_{1}+b_{2}\right)\right. \\
\left.+r_{b} b_{2}\right]+\frac{1}{M}\left(b_{2}-b_{1}\right) t a
\end{gathered}
$$

$$
\begin{aligned}
{\left[b_{2}\left(4+3 r_{b}\right)+\frac{2}{b_{1}}\right.} & \left.\left(1+r_{b}\right)\left(3 b_{1}{ }^{2}-b_{2}{ }^{2}\right)\right] \\
& +\left(b_{2}-b_{1}\right)(A+D)\left(2 w_{s}+m-c\right) \\
& +a, \\
\pi_{s}{ }^{*}\left(w_{s}\right)^{\prime \prime} & =2\left(b_{2}-b_{1}\right)(A+D)<0 .
\end{aligned}
$$

Among them, $\mathrm{A}=\frac{1}{M}\left(b_{1}-b_{2}\right)\left(1+r_{b}\right)\left(4 b_{1}+4 b_{2}+\right.$ $\left.r_{b} b_{2}\right) \quad, \quad \mathrm{D}=\frac{1}{b_{1} M}\left(b_{1}-b_{2}\right)\left(1+r_{b}\right)\left[2\left(b_{1}+b_{2}\right)^{2}+\right.$ $\left.b_{1} r_{b}\left(2 b_{1}+b_{2}\right)\right], \quad \mathrm{M}=8\left(b_{1}{ }^{2}-b_{2}{ }^{2}\right)\left(1+r_{b}\right)-r_{b}{ }^{2} b_{2}{ }^{2}$.

From $\pi_{s}{ }^{*}\left(w_{s}\right)^{\prime \prime}<0$, it can be obtained that $\pi_{s}{ }^{*}\left(w_{s}\right)$ is a concave function on $w_{s}$. So make $\pi_{s}{ }^{*}\left(w_{s}\right)=$ 0 , we can get the optimal decision, namely, you can get the optimal decision $w_{s}{ }^{*}$ of suppliers wholesale price. Then it is substituted into $w_{m}{ }^{*}, p_{m}{ }^{*}, p_{r}{ }^{*}$ and the following conclusions can be obtained:

Proposition 3. In decentralized decision making, for the two channel supply chain of the retailer's initial free funds shortage, when the interest rate $r_{b}$ is taken to the loan payment method, the optimal decision of the suppliers, the manufacturers and the retailers $w_{s}{ }^{*}, w_{m}{ }^{*}, p_{m}{ }^{*}, p_{r}{ }^{*}$ is obtained respectively:

$$
\begin{aligned}
w_{s}{ }^{*}=\frac{a}{2(A+D)} & \left(b_{1}-b_{2}\right) \\
& -\frac{a}{2 M(A+D)}[(1-t)(1 \\
& \left.+r_{b}\right)\left[4\left(b_{1}+b_{2}\right)+r_{b} b_{2}\right] \\
& +t\left[b_{2}\left(4+3 r_{b}\right)\right. \\
& \left.\left.+\frac{2}{b_{1}}\left(1+r_{b}\right)\left(3 b_{1}{ }^{2}-b_{2}{ }^{2}\right)\right]\right] \\
& +\frac{1}{2}(c-m), \\
p_{m}{ }^{*}=\frac{a A}{2(A+D)} & \left(b _ { 1 } \frac { - b _ { 2 } ) } { M } \left[4(1-t)\left(1+r_{b}\right) b_{1}\right.\right. \\
& +\frac{\left.\left(4+3 r_{b}\right) t a b_{2}\right]}{} \\
& +(4)[(1-t)(1 \\
& -\frac{a A}{2 M(A+D)}\left[\left(b_{1}+b_{2}\right)+r_{b} b_{2}\right] \\
& \left.+r_{b}\right)\left[4\left(b_{1}\right)\right. \\
& +t\left[b_{2}\left(4+3 r_{b}\right)\right. \\
& \left.\left.+\frac{2}{b_{1}}\left(1+r_{b}\right)\left(3 b_{1}{ }^{2}-b_{2}{ }^{2}\right)\right]\right] \\
& +\frac{1}{2} A(c+m),
\end{aligned}
$$




$$
\begin{aligned}
& w_{m}{ }^{*}=\frac{1}{b_{1} M}\left[2 b_{1} b_{2}\left(2+r_{b}\right)(1-t) a\right. \\
& +\left(4 b_{1}{ }^{2}+b_{2}{ }^{2} r_{b}\right) t a \\
& +\left(b_{1}-b_{2}\right)\left(4 b_{1}{ }^{2}+4 b_{1} b_{2}-b_{2}{ }^{2} r_{b}\right. \\
& +2 b_{1} b_{2} r_{b} \\
& \left.+4 b_{1}{ }^{2} r_{b}\right)\left[\frac{a}{2(A+D)\left(b_{1}-b_{2}\right)}\right. \\
& -\frac{a}{2 M(A+D)}[(1-t)(1 \\
& \left.+r_{b}\right)\left[4\left(b_{1}+b_{2}\right)+r_{b} b_{2}\right] \\
& +t\left[b_{2}\left(4+3 r_{b}\right)\right. \\
& \left.\left.+\frac{2}{b_{1}}\left(1+r_{b}\right)\left(3 b_{1}{ }^{2}-{b_{2}}^{2}\right)\right]\right] \\
& \left.+\frac{1}{2}(c+m)\right] \text {, } \\
& p_{r}{ }^{*}=\frac{a D}{2(A+D)\left(b_{1}-b_{2}\right)} \\
& +\frac{a\left(1+r_{b}\right)}{b_{1} M}\left[b_{1} b_{2}\left(4+r_{b}\right)(1-t)\right. \\
& \left.+2\left(3 b_{1}^{2}-b_{2}^{2}\right) t\right] \\
& -\frac{a D}{2 M(A+D)}[(1-t)(1 \\
& \left.+r_{b}\right)\left[4\left(b_{1}+b_{2}\right)+r_{b} b_{2}\right] \\
& +t\left[b_{2}\left(4+3 r_{b}\right)\right. \\
& \left.\left.+\frac{2}{b_{1}}\left(1+r_{b}\right)\left(3{b_{1}}^{2}-b_{2}{ }^{2}\right)\right]\right] \\
& +\frac{1}{2} D(c+m) \text {. }
\end{aligned}
$$

Among them, $\mathrm{A}=\frac{1}{M}\left(b_{1}-b_{2}\right)\left(1+r_{b}\right)\left(4 b_{1}+4 b_{2}+\right.$ $\left.r_{b} b_{2}\right) \quad, \quad \mathrm{D}=\frac{1}{b_{1} M}\left(b_{1}-b_{2}\right)\left(1+r_{b}\right)\left[2\left(b_{1}+b_{2}\right)^{2}+\right.$ $\left.b_{1} r_{b}\left(2 b_{1}+b_{2}\right)\right], \quad \mathrm{M}=8\left(b_{1}{ }^{2}-{b_{2}}^{2}\right)\left(1+r_{b}\right)-r_{b}{ }^{2} b_{2}{ }^{2}$.

By comparing the optimal pricing decision of the loan payment financing model with the deferred payment financing model, the following conclusions can be obtained:

Proposition 4. When retailers of dual channel three-tier supply chain are lack of funds, if the deferred payment interest rates are equal to the lending rates, that is $\delta=r_{b}$, there are $p_{r}{ }^{1}-p_{r}{ }^{*} \leq 0,, w_{m}{ }^{1}-w_{m}{ }^{*} \leq$ $0, d_{r}{ }^{1}-d_{r}{ }^{*} \geq 0$.

From the conclusion above, when deferring payment interest rate is equal to lending rate, comparing with the lending mode, if the retailers choose to defer the payment, retailers can obtain goods at lower wholesale prices and consumers of retail channels can also benefit from it (at a lower price to obtain the necessary goods). Because lower retail price attracts more demand, the demand for retail sales channels is increased, the market for retailers is expanded and market share is improved. Thus generally, there are:
Corollary 1. If $\delta=r_{b}$, in the decentralized decision-making of the dual channel supply chain under the retailer funds constraints, the underfunded retailers choose to postpone payment.

Proof. If we want to prove that retailers will choose to defer the payment mode, we only need to prove that under the optimal decision of the two models, more profit can be obtained with retailers delayed payment model. That is $\pi_{r}(\delta)^{*} \geq \pi_{r}\left(r_{b}\right)^{*}$. When the delayed payment interest rate is equal to the lending rate $\delta=r_{b}$, the profit function of retailers decentralized decision can be expressed as follows:

$$
\begin{gathered}
\pi_{r}(\delta)^{*}=\frac{B}{w_{m}(\delta)^{*}}\left(p_{r}(\delta)^{*}\right. \\
\left.-w_{m}(\delta)^{*}\right) \\
+\left[p_{r}(\delta)^{*}-(1+\delta) w_{m}(\delta)^{*}\right]\left(d_{r}(\delta)^{*}\right. \\
\left.\quad-\frac{B}{w_{m}(\delta)^{*}}\right) \\
=\left(p_{r}(\delta)^{*}-(1+\delta) w_{m}(\delta)^{*}\right) d_{r}(\delta)^{*}+\delta B, \\
\pi_{r}\left(r_{b}\right)^{*}=\left(p_{r}\left(r_{b}\right)^{*}-w_{m}\left(r_{b}\right)^{*}\right) d_{r}\left(r_{b}\right)^{*} \\
-\left(w_{m}\left(r_{b}\right)^{*} d_{r}\left(r_{b}\right)^{*}-B\right) r_{b} \\
=\left(p_{r}\left(r_{b}\right)^{*}-\left(1+r_{b}\right) w_{m}\left(r_{b}\right)^{*}\right) d_{r}\left(r_{b}\right)^{*}+r_{b} B .
\end{gathered}
$$

Proposition 4. It shows that $d_{r}(\delta)^{*}-d_{r}\left(r_{b}\right)^{*} \geq 0$, so when $\delta=r_{b}$, we need to prove that in delayed payment mode, insufficient funds of retailers will have higher marginal revenue. That is $p_{r}(\delta)^{*}-(1+\delta) w_{m}(\delta)^{*} \geq$ $p_{r}\left(r_{b}\right)^{*}-\left(1+r_{b}\right) w_{m}\left(r_{b}\right)^{*}$, and we can just substitute the specific decision variables into it.

In the decentralized decisions of the dual channel supply chain under capital constraint of retailers, retailers have the right to choose the financing mode of solving the problem of lack of funds. According to proposition 4 and corollary 1 , it can be obtained that when delay payment interest rate is equal to lending rate, retailers under delay payment financing mode will get more profits, so retailers will give preference to delay payment financing mode. In addition, in order not to affect the sales demand, compared with capital adequacy, in the delayed payment financing mode, manufacturers will reduce wholesale price at a rate and increase demand for retailers. Sales price and demand of retail channel and direct selling channel and suppliers' wholesale price will not be affected by the retailers' capital constraints. Therefore, the total revenue of suppliers will not be affected. However, whether the retailer can choose to defer payment also need to consider the manufacturer's decisions and whether the manufacturer is willing to provide the opportunity to delay payment, we need to discuss the manufacturers' earnings under the deferred payment and lending model respectively.

\section{Example analysis}

In the last Chapter, we first construct the pricing decision models of suppliers, producers and retailers in supply chain under sufficient capital. Secondly, we discuss the pricing decisions of suppliers, manufacturers and retailers through theoretical analysis under the insufficient initial free funds of retailers B, in the delayed payment and bank 
loan financing mode. This section further explores the relationship between the decision variables and the optimal profit through numerical simulations. Make model parameter values for $a=1000, t=0.6, \mathrm{c}=3$, $b_{1}=8, b_{2}=2, m=1$.

\subsection{The comparison of capital adequacy pricing decisions and deferred payment pricing decisions}

First compare in the decentralized decision making wellfunded pricing decisions of the supply chain with the pricing decisions under the delayed payment financing mode. And through numerical substitution and calculation, it can be obtained that the optimal selling price of manufacturers and retailers under capital constrained is equal to the optimal decision of well-funded retailers, as follows:

$$
p_{m}{ }^{0}=p_{m}{ }^{1}=57.54, p_{r}{ }^{0}=p_{r}{ }^{1}=78.46 \text {. }
$$

And in the delayed payment the optimal wholesale price of the manufacturers $w_{m}{ }^{1}$ and the optimal decisionmaking price $w_{m}{ }^{0}$ under adequate capital meet the following equation:

$$
w_{m}^{1}=\frac{w_{m}^{0}}{1+\delta}=\frac{67.54}{1+\delta} .
$$

Because information is symmetrical among enterprises in dual channel supply chain, if retailers choose to defer the payment, direct selling channel price and retail price are not affected by retailers' capital constraints, and retail and direct sales demand will also not affected by retailers' capital constraints. So there are $1=d_{m}{ }^{0}=$ 96.62, $d_{r}{ }^{1}=d_{r}{ }^{0}=87.38$. Therefore, direct sales revenue of manufacturers and sales revenue of retailers are unchanged.

However, the financial constraints of retailers will reduce manufacturers' wholesale price for the retailers. The increase of delayed payment interest rate will reduce the marginal profit of retailers selling goods, which will reduce the retailers ordering enthusiasm and affect the manufacturer's wholesale revenue. Therefore, manufacturers will correspondingly lower wholesale prices for retailers and encourage retailers to improve commodity ordering quantity.

Through the calculation it can be known that in the deferred payment financing model, the supplier's revenue is $\pi_{s}{ }^{1}=\pi_{s}{ }^{0}=6944.90$, the manufacturer's revenue is $\pi_{m}{ }^{1}=\pi_{r}{ }^{0}-\delta B=3779.90-\delta \mathrm{B}$, and the retailer's revenue is $\pi_{r}{ }^{1}=\pi_{r}{ }^{0}+\delta B=954.54+\delta B$.

\subsection{Table analysis of delay payment financing pricing decision and loan financing pricing decision}

According to optimal decision expression of suppliers, manufacturers and retailers under defer payment model and loan payment model (proposition 2.2, 2.3), it can be obtained that through numerical substitution, the relationship between the optimal decision variable and the rate of payment (including the delay payment interest rate and lending rate) for suppliers, manufacturers and retailers in decentralized decisions making. When $\delta=\mathrm{r}_{\mathrm{b}}$ takes $0.1,0.2,0.3,0.4$, it can be obtained that the relationship between payment rate and decision variable and the optimal profit of the retailers, manufacturers and suppliers in the delay payment model and the loan payment mode, respectively indicating as Table 1 .

The relationship between the optimal decision variables and their profit in $\delta=\mathrm{r}_{\mathrm{b}}$ under the deferred payment model and the credit payment model is shown in Table 2. Among them, $\Delta \mathrm{w}_{\mathrm{s}}{ }^{*}=\mathrm{w}_{\mathrm{s}}{ }^{1}-\mathrm{w}_{\mathrm{s}}{ }^{*}, \Delta \mathrm{w}_{\mathrm{m}}{ }^{*}=$ $\mathrm{w}_{\mathrm{m}}{ }^{1}-\mathrm{w}_{\mathrm{m}}{ }^{*}, \Delta \mathrm{p}_{\mathrm{m}}{ }^{*}=\mathrm{p}_{\mathrm{m}}{ }^{1}-\mathrm{p}_{\mathrm{m}}{ }^{*}, \quad \Delta \mathrm{p}_{\mathrm{r}}{ }^{*}=\mathrm{p}_{\mathrm{r}}{ }^{1}-\mathrm{p}_{\mathrm{r}}{ }^{*}$, $\Delta \mathrm{d}_{\mathrm{r}}{ }^{*}=\mathrm{d}_{\mathrm{r}}{ }^{1}-\mathrm{d}_{\mathrm{r}}{ }^{*}, \Delta \mathrm{d}_{\mathrm{m}}{ }^{*}=\mathrm{d}_{\mathrm{m}}{ }^{1}-\mathrm{d}_{\mathrm{m}}{ }^{*}, \Delta \pi_{\mathrm{r}}{ }^{*}=\pi_{\mathrm{r}}{ }^{1}-$ $\pi_{\mathrm{r}}{ }^{*}, \Delta \pi_{\mathrm{m}}{ }^{*}=\pi_{\mathrm{m}}{ }^{1}-\pi_{\mathrm{m}}{ }^{*}, \Delta \pi_{\mathrm{s}}{ }^{*}=\pi_{\mathrm{s}}{ }^{1}-\pi_{\mathrm{s}}{ }^{*}$.

From table 3, when the delayed payment interest rate is equal to the lending rate, the optimal profit of suppliers and retailers in the delayed payment financing model is more than that in the loan financing mode. And with the increase of the interest rate, each can get more profits. However, manufacturer's optimal profit depends on the number of initial free money of the retailers. When initial free funds of retailers are fixed value, there is a maximal value of interest rate. If the delayed payment interest rates and lending rates are higher than the maximal interest rate at the same time, manufacturers can make more profits in the loan financing mode of the retailers. Therefore, in this situation, the manufacturers will not provide the delayed payment financing mode.

\subsection{Graphical analysis of the pricing decision making in the deferred payment financing mode and the loan financing mode}

In order to further clearly describe how effectively the financing and pricing decisions are making for the suppliers, manufacturers and retailers in different payment rates. Next, we will extend the payment rate $\delta, \mathrm{r}_{\mathrm{b}}$ to the interval $(0,0.8)$, and take the payment rate as the horizontal coordinate, and the price, the demand or its profit as the ordinate. And we can get the price decision, demand and profit scatter plot with smooth line of suppliers, manufacturers and retailers in the defer payment and loan financing mode using excel statistical tool.

Figs. $1 \sim 4$ show the curve of the relationship between the pricing decisions of suppliers, manufacturers and retailers and different interest rates in delayed payment and loan financing mode. Figs 5 and 6 give the curve of the relationship between the sales demand of manufacturers and retailers and different interest rates in delayed payment and loan financing mode. Figs. 7 and 8 also give the curve of the relationship between the profits of suppliers and retailers and different interest rates in delayed payment and loan financing model. Among them the solid line represents the deferred payment financing model, and dashed line represents the loan financing model. 


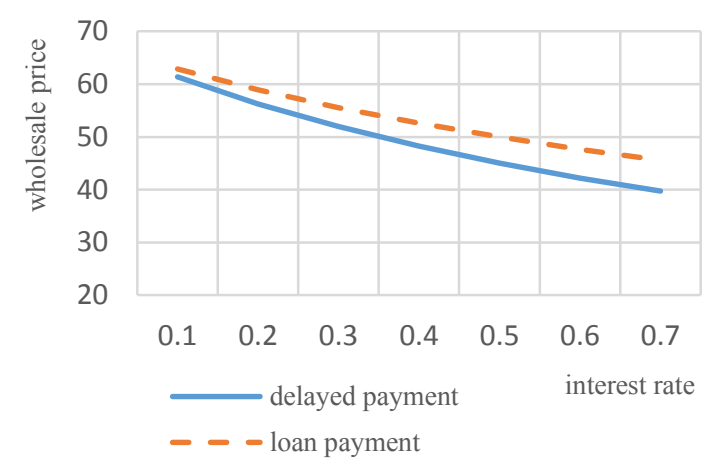

Fig.1. Wholesale price of suppliers

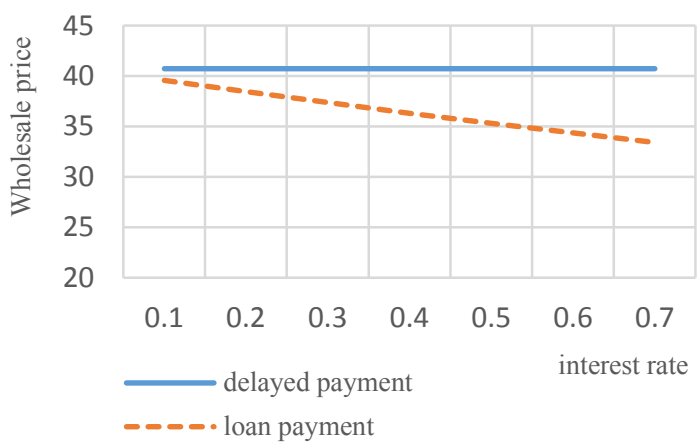

Fig.2. Wholesale price of manufacturers

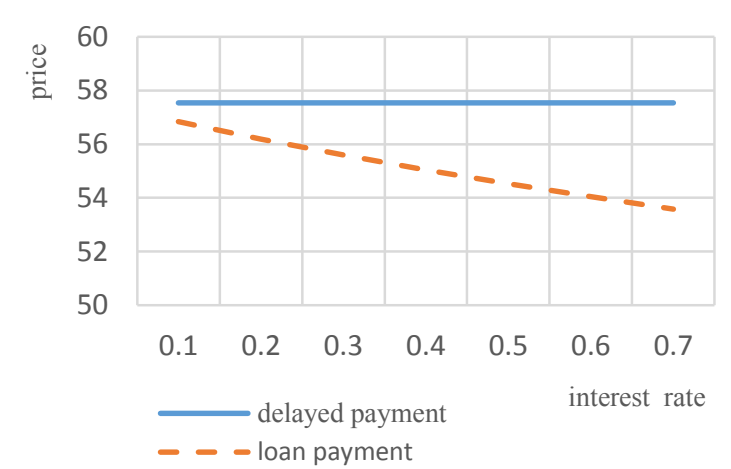

Fig.3. Direct selling price of manufacturers

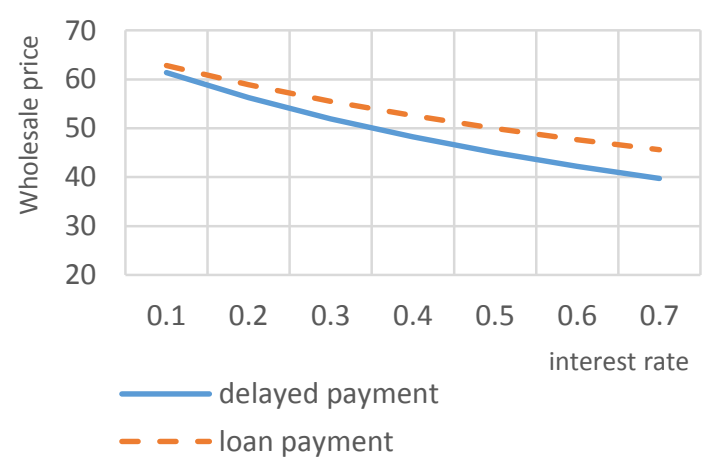

Fig.4. Retail price

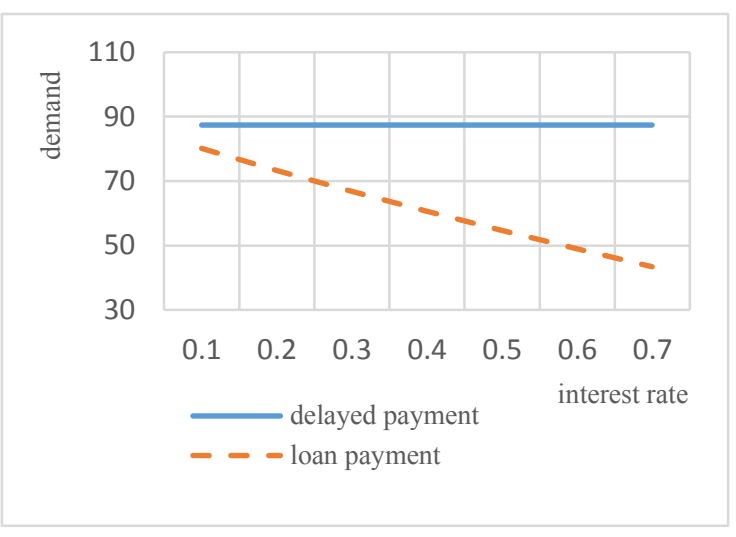

Fig.5. Demand of retailers

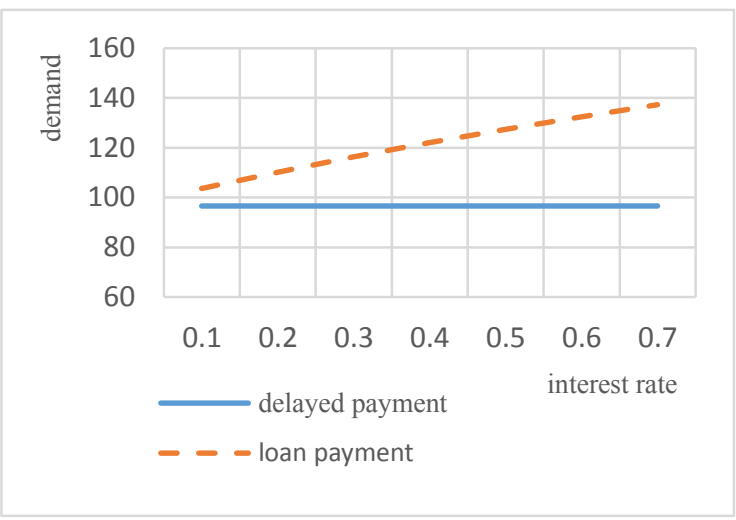

Fig.6. Demand of manufacturers

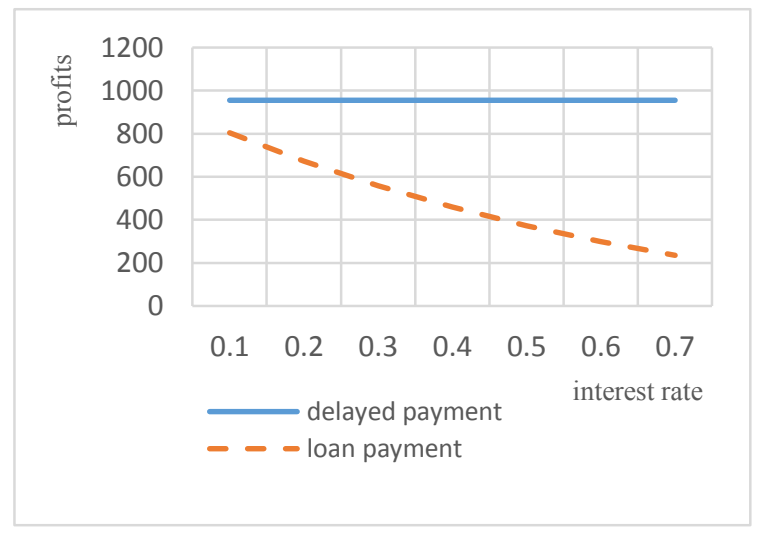

Fig.7. Profits of retailers

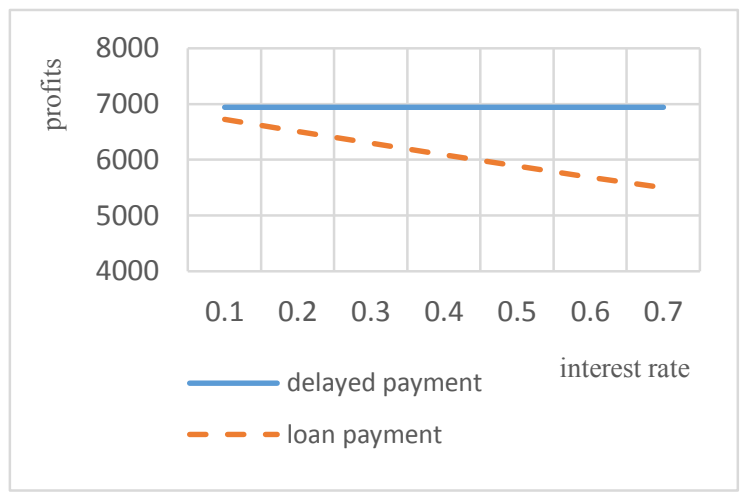

Fig. 8. Profits of suppliers 
From table 2 and figure (1) (4), figure (5) and (6), figure (7) and (8), in general the following conclusions can be obtained: On the premise that the delayed payment interest rate $\delta$ is equal to the loan interest rate $r_{b}$, retailers prefer to the defer payment financing mode. At the same time the supplier also hope that retailers choose to defer payment financing mode. As for the manufacturers, they will make decisions according to the initial free funds of retailers. The specific analyses are as follows:

For the retailers, on the one hand, in the delayed payment financing mode, retailers of insufficient funds obtain goods at relatively lower wholesale prices of manufacturers, and sell the goods at a discount of the retail price so that consumers of the retail channel can get benefits, more customers can be attracted, the demand of retail channel will be expanded and market share and influence of the retailers will be improved; on the other hand, under the deferred payment financing model, the profit benefit is greater than that of the loan financing model. So retailers will choose the financing model which are conducive to maximize revenue. Therefore, in the decentralized decision-making, Capital-constrained retailers choose to work with manufacturers to accept the deferred payment financing mode.

For the suppliers, if retailers accept the deferred payment financing model, suppliers can sell goods at higher wholesale prices to manufacturers and the total sale of suppliers is unchanged. Through comparison, we can see an increase in supplier's optimal profits. Therefore, at the same rate, suppliers will also wish that the retailers choose the delayed payment financing mode.

For manufacturers, at a certain rate of payment in the delayed payment mode, optimal profit of the manufacturers is inversely proportional to the initial free capital of the retailers; by comparing the optimal profits in the delayed payment financing mode and loan financing mode, whether manufacturers cooperate with retailers to offer the deferred payment financing mode depends on the number of the retailer's initial free funds. When the interest rate is certain, if the initial free capital of the retailers is not greater than a certain value, the manufacturers can make more profits in the deferred payment financing mode. And the smaller the initial free capital of the retailers is, the greater profits the manufacturers will gain. It also shows that manufacturers are more willing to work with retailers to provide the delayed payment financing mode when the retailers are severely underfunded.

\section{Conclusions and future work}

This paper chooses the three-stage supply chain consisting of a single supplier, a single manufacturer and a single retailer as the research object, and makes theoretical research and numerical analysis on the financing decisions and pricing in the supply chain of retailers under the capital constraints. Firstly, the profit model for each member of the three-tier supply chain of dual channel sales is constructed under capital adequacy. Then, the profit model of each member of the supply chain under the deferred payment financing mode and loan financing mode is constructed respectively to compare which is more advantageous between the two financing modes. It can be found through comparison analysis of theoretical model and the method of numerical simulation as follows:

In the premise that the delayed payment interest rate $\delta$ is equal to the loan interest rate $r_{b}$, the retailers will prefer to choose the delay payment financing mode. On the one hand, the retailers will gain more profits under the deferred payment model than the loan financing model; On the other hand, in the delayed payment financing mode, retailers of insufficient funds obtain goods at relatively lower wholesale prices of manufacturers, and sell the goods at a discount of the retail price so that consumers of the retail channel can get benefits, more customers can be attracted, the demand of retail channel will be expanded and market share and influence of the retailers will be improved. At the same time the supplier also hope that retailers choose to defer payment financing mode. As for the manufacturers, they will make decisions according to the initial free funds of retailers. But manufacturers are more willing to work with retailers to provide the delayed payment financing mode when the retailers are severely underfunded. And then, the optimal choice of the manufacturers is the deferred payment contract without compensation (deferred payment interest rate is 0 ) to make the profits optimal.

Although this paper comes to some significant conclusions through model studies, the research still has its limitations. First, this paper studies the decentralized decision-making of the supply chain members, and is not related to the centralized decision-making problems of supply chain members. When analyzing the capital constraints problems of retailers, it can be obtained that the retailers can get more profits in the deferred payment financing mode than the loan financing mode. Under certain conditions of decentralized decision-making, the manufacturers are willing to provide the deferred payment financing mode. However, we also need to consider the decisions of the suppliers from the centralized decisionmaking to study if they are still willing to provide the delayed payment financing mode. This is what can continue to be studied in the future. Secondly, this paper focuses on the supply chain of a single supplier, a single manufacturer and a single retailer, which is still simplified compared with the supply chain in the real environment. Therefore, in the later work, the research object can be extended to multiple suppliers, multiple manufacturers and multiple retailers, and initial funding constraints can also be extended to the manufacturers and retailers at the same time. In addition, this paper shows simple ways of finance services the delayed payment financing mode and the loan financing mode. With the continuous innovation and development of supply chain finance, the financing modes will become diversified. Therefore, in the later work, the issue of pricing decision and operation research with capital constraints under other new financing modes can also be considered. 


\section{References}

1. H.Y. Tu, G.W. Hua, S.Y. Wang. Research on financing and production decisions in the supply chain of capital constraints. Systems Science and Mathematics, 2011, 31(11): 1414-1422.

2. A.M. Zhao, M. Li. Research on the financing and pricing of the supply chain under the condition of noncompetition. Management Science in China, 2012, 20: 521-527.

3. X.F. Chen, D.L. Zhu, W.J. Ying. Research on capital constraint and financing and operation comprehensive decision-making in the supply chain. Journal of Management Science, 2016, 11(3): 70-77.

4. N. Yan, B. Sun. Coordinating loan strategies for supply chain financing with limited credit. OR Spectrum, 2013, 35: 1039-1058.

5. K. Li, W.H. Chen. Pricing policy of multi-channel supply chain for funds constraints of retailers. Operations Research and Management, 2015, 36 (10): 1511-1515.

6. Y.Q. Song, W.L. Wang. Financing model and risk prevention of suppliers under capital constraints. Commercial Economy, 2017, (12): 46-48.

7. Y.G. Zhang, X.W. Tang. Study on the wholesale price contract of short life cycle products under the deferred payment. Management Science, 2011, 19(3): 63-69.

8. X. Zhang, Q. Lin. Research on the optimal decision making in the three-stage supply chain with the delayed payment and order financing. Journal of Systems Engineering, 2015, 39(02): 405-409.

9. Y.D. Gong, B.Y. Li, W.X. Li. Research on the three-stage supply chain coordination and profit distribution mechanism. Statistics and Decision, 2013, 23(1): 185-186.

10. H. Wang, J. Zhou. Research on decision making of dual channel supply chain under different price modes. China Management Science, 2009, 17(6): 84-90.

11. V. Babich, G. Aydin, Y. Brunet. Risk, financing and the optimal number of suppliers. Supply Chain Disruptions, 2012, (32): 195-240.

12. W.L. Wang, J.W. Luo. Research on the prepayment financing strategy of supply chain based on price discount. Journal of Management Science, 2014, 17(11): 20-32.

13. J.Z. Zhan, X.Z. Zhou, Y.D. Gong. The optimal financing and production decisions of the supply chain of production capital constraints. Journal of Systems Engineering, 2015, 30(2): 190-201.

14. S.Z. Bai, N. Xu, Z.H. Yan. Research on supply chain coordination based on inventory pledge financing mode. Operations Research and Management, 2013, 22(3): 185-193.

15. Y.H. Fu, X.F. Wang, G.H. Chen. Financing options in the supply chain for inventory financing and credit loan under the buyback coordination. System Engineering, 2014, 32(11): 44-49. 
Table 1. The decision variables and profits in the deferred payment model.

\begin{tabular}{|c|c|c|c|c|c|c|c|c|c|}
\hline $\boldsymbol{\delta}$ & $\boldsymbol{w}_{\boldsymbol{s}}^{\mathbf{1}}$ & $\boldsymbol{w}_{\boldsymbol{m}}{ }^{\mathbf{1}}$ & $\boldsymbol{p}_{\boldsymbol{m}}{ }^{\mathbf{1}}$ & $\boldsymbol{p}_{\boldsymbol{r}}{ }^{\mathbf{1}}$ & $\boldsymbol{d}_{\boldsymbol{r}} \mathbf{d}^{\mathbf{1}}$ & $\boldsymbol{d}_{\boldsymbol{m}}$ & $\boldsymbol{\pi}_{\boldsymbol{r}}{ }^{\mathbf{1}}$ & $\boldsymbol{\pi}_{\boldsymbol{m}} \mathbf{1}^{\mathbf{1}}$ & $\boldsymbol{\pi}_{\boldsymbol{s}}{ }^{\mathbf{1}}$ \\
\hline $\mathbf{0 . 1}$ & 40.74 & 61.40 & 57.54 & 78.46 & 87.38 & 96.62 & $\begin{array}{c}954.54 \\
+0.1 B\end{array}$ & $\begin{array}{c}3,779.90 \\
-0.1 \mathrm{~B}\end{array}$ & 6944.90 \\
\hline $\mathbf{0 . 2}$ & 40.74 & 56.28 & 57.54 & 78.46 & 87.38 & 96.62 & $\begin{array}{c}954.54 \\
+0.2 B\end{array}$ & $\begin{array}{c}3,779.90 \\
-0.2 \mathrm{~B}\end{array}$ & 6944.90 \\
\hline $\mathbf{0 . 3}$ & 40.74 & 51.95 & 57.54 & 78.46 & 87.38 & 96.62 & $\begin{array}{c}954.54 \\
+0.3 B\end{array}$ & $\begin{array}{c}3,779.90 \\
-0.3 \mathrm{~B}\end{array}$ & 6944.90 \\
\hline $\mathbf{0 . 4}$ & 40.74 & 48.24 & 57.54 & 78.46 & 87.38 & 96.62 & $\begin{array}{c}954.54 \\
+0.4 B\end{array}$ & $\begin{array}{c}3,779.90 \\
-0.4 \mathrm{~B}\end{array}$ & 6944.90 \\
\hline
\end{tabular}

Table 2. The decision variables and profits in the loan financing model.

\begin{tabular}{|c|c|c|c|c|c|c|c|c|c|}
\hline $\boldsymbol{r}_{\boldsymbol{b}}$ & $\boldsymbol{w}_{\boldsymbol{s}}{ }^{*}$ & $\boldsymbol{w}_{\boldsymbol{m}}{ }^{*}$ & $\boldsymbol{p}_{\boldsymbol{m}}{ }^{*}$ & $\boldsymbol{p}_{\boldsymbol{r}}{ }^{*}$ & $\boldsymbol{d}_{\boldsymbol{r}}{ }^{*}$ & $\boldsymbol{d}_{\boldsymbol{m}}{ }^{*}$ & $\boldsymbol{\pi}_{\boldsymbol{r}}{ }^{*}$ & $\boldsymbol{\pi}_{\boldsymbol{m}}{ }^{*}$ & $\boldsymbol{\pi}_{\boldsymbol{s}}{ }^{*}$ \\
\hline $\mathbf{0 . 1}$ & 39.59 & 62.87 & 56.84 & 79.19 & 80.19 & 103.67 & $\begin{array}{c}803.83 \\
+0.1 \mathrm{~B}\end{array}$ & 3472.15 & 6726.60 \\
\hline $\mathbf{0 . 2}$ & 38.46 & 58.93 & 56.19 & 79.88 & 73.35 & 110.21 & $\begin{array}{l}672.54 \\
+0.2 \mathrm{~B}\end{array}$ & 3271.83 & 6509.31 \\
\hline $\mathbf{0 . 3}$ & 37.37 & 55.53 & 55.60 & 80.55 & 66.83 & 116.32 & $\begin{array}{c}558.30 \\
+0.3 \mathrm{~B}\end{array}$ & 3149.94 & 6295.55 \\
\hline $\mathbf{0 . 4}$ & 36.33 & 52.58 & 55.04 & 81.19 & 60.60 & 122.04 & $\begin{array}{c}459.11 \\
+0.4 \mathrm{~B}\end{array}$ & 3086.07 & 6086.91 \\
\hline
\end{tabular}

Table 3. The relationship between the optimal variable value of the deferred payment model and the loan payment model in $\delta=r_{b}$.

\begin{tabular}{|c|c|c|c|c|c|c|c|c|c|}
\hline $\boldsymbol{\delta}=\boldsymbol{r}_{\boldsymbol{b}}$ & $\Delta \boldsymbol{w}_{\boldsymbol{s}}{ }^{*}$ & $\Delta \boldsymbol{w}_{\boldsymbol{m}}{ }^{*}$ & $\Delta \boldsymbol{p}_{\boldsymbol{m}}{ }^{*}$ & $\Delta \boldsymbol{p}_{\boldsymbol{r}}{ }^{*}$ & $\Delta \boldsymbol{d}_{\boldsymbol{r}}{ }^{*}$ & $\Delta \boldsymbol{d}_{\boldsymbol{m}}{ }^{*}$ & $\Delta \boldsymbol{\pi}_{\boldsymbol{r}}{ }^{*}$ & $\Delta \boldsymbol{\pi}_{\boldsymbol{m}}{ }^{*}$ & $\Delta \boldsymbol{\pi}_{\boldsymbol{s}}{ }^{*}$ \\
\hline $\mathbf{0 . 1}$ & 1.16 & -1.48 & 0.70 & -0.72 & 7.19 & -7.05 & 150.71 & $\begin{array}{c}307.75 \\
-0.1 \mathrm{~B}\end{array}$ & 218.30 \\
\hline $\mathbf{0 . 2}$ & 2.28 & -2.64 & 1.35 & -1.42 & 14.03 & $\begin{array}{c}- \\
13.59\end{array}$ & 282.00 & $\begin{array}{c}508.06 \\
-0.2 \mathrm{~B}\end{array}$ & 435.59 \\
\hline $\mathbf{0 . 3}$ & 3.37 & -3.58 & 1.94 & -2.08 & 20.55 & $\begin{array}{c}- \\
19.70\end{array}$ & 396.24 & $\begin{array}{c}629.95 \\
-0.3 \mathrm{~B}\end{array}$ & 649.34 \\
\hline $\mathbf{0 . 4}$ & 4.42 & -4.34 & 2.50 & -2.72 & 26.78 & $\begin{array}{c}- \\
25.42\end{array}$ & 495.43 & $\begin{array}{c}693.82 \\
-0.4 \mathrm{~B}\end{array}$ & 857.99 \\
\hline
\end{tabular}

